\title{
M.S. Andersson and M.C. de Vicente: Gene flow between crops and their wild relatives
}

\author{
The Johns Hopkins University Press, Baltimore 2010, XV + 564 pp. ISBN \\ 9780801893148, Prize 60.00 US \$
}

F. Nuez

Received: 19 January 2011 / Accepted: 21 January 2011/Published online: 12 March 2011

(C) Springer Science+Business Media B.V. 2011

Gene flow between crops and their relatives is a matter of increasing interest regarding aspects of environment, conservation of genetic resources and plant breeding, among others. Quantifying gene flow between transgenic crops and wild flora as well as the analysis of aspects that condition this exchange are key aspects on the decision making on the protection of wild flora and fauna. The issue is also relevant for the conservation of genetic resources both in situ and on farm and ex situ. Their understanding allows the establishment of safe distances and adequate isolation methods. This type of information is also useful for breeders, specifically in aspects related to extraspecific variation.

The Andersson and de Vicente's book is an important effort of synthesis of nearly twenty crops. Most of the transgenic crops currently cultivated are included. The information presented is structured in a logical and coherent manner: centres of origin and diversity, reproductive biology, primary, secondary and tertiary gene pools, outcrossing rates and isolation distances, cultivated transgenic crops and practical recommendations. The information is updated and the references section is complete.

From the point of view of plant breeders there are very useful references to biotechnological methods, as embryo rescue to overcome crossability barriers in order to exploit the secondary and tertiary gene pools. However, the book lacks information regarding horticultural crops (vegetables and fruit trees), so many important in agriculture.

Apart of this deficiency the book will be a manual of interest for environmental biologists, curators of germplasm and plant breeders. They will have a huge quantity of valuable information in a concise, clear and updated manner.

F. Nuez $(\square)$

Valencia, Spain

e-mail: fnuez@btc.upv.es 